F C Donders Institute of Ophthalmology, Faculty of Medicine, Utrecht University, Netherlands G Porro

D Wittebol-Post W F Treffers

Department of Child Neurology, Faculty of Medicine, Utrecht

University,

Netherlands

O Van Nieuwenhuizen

Department of Pediatrics, Workgroup Infantile

Encephalopathy,

Utrecht University,

Netherlands

A J F Schenk-Rootlieb

Department of

Ethology and

Socio-ecology, Faculty

of Biology, Utrecht

University,

Netherlands

E M Dekker

M B H Schilder

Correspondence to: Dr G Porro, Department of Ophthalmology, Utrecht University Hospital, Heidelberglaan 100, 3584 CX Utrecht, Netherlands.

Accepted for publication 15 April 1998

\title{
Visual behaviours of neurologically impaired children with cerebral visual impairment: an ethological study
}

G Porro, E M Dekker, O Van Nieuwenhuizen, D Wittebol-Post, M B H Schilder, A J F Schenk-Rootlieb, W F Treffers

\begin{abstract}
Backgroundlaims-Visual functions of neurologically impaired children with permanent cerebral visual impairment (CVI) can be difficult to determine. This study investigated the behavioural profile of CVI children by means of ethological observations in order to gain a better understanding of their visual functions.

Methods-Video registrations of nine subjects who were unable to undergo more orthodox methods of visual function testing were observed and analysed by an ethologist.

Results-A series of behaviours (direct signs) and supportive or confirming behavioural elements (indirect signs) indicating some visual perception in the children were found.

Conclusion-Detailed ethological observations of visual behaviour were shown to be useful for analysing visual functions of children with permanent CVI.

(Br F Ophthalmol 1998;82:1231-1235)
\end{abstract}

Cerebral visual impairment (CVI) is a disturbance of vision caused by a defective function of the retrochiasmatic part of the visual system in the absence of any important ocular disease. ${ }^{1}$ In recent years, several authors have described the development of visual function in neurologically impaired children affected by CVI. ${ }^{1-13}$ Standard and behavioural techniques used for quantifying visual function are, however, not always applicable in this group of children. In fact, subjects with permanent CVI may lack the ability to maintain a stable fixation at a desired point or may be unable to direct their gaze to the stimulus location. Interpretation of their visual functions can be a perplexing problem for ophthalmologists.

Several visual behaviours characteristic of CVI, such as avoiding, ${ }^{14}{ }^{15}$ chaotic eye movements, ${ }^{16}$ faking, ${ }^{17}$ overlooking, ${ }^{18}$ head shaking, ${ }^{19}$ and squeezing the eyelid as a result of photophobia ${ }^{20}$ have been reported in the literature. However, visual behaviour of children with CVI has not yet been studied by means of an ethological analysis.
Ethology is a scientific study of animal (and human) behaviour which focuses itself on forming questions - namely, the proximate and the ultimate causation of behaviours or ontogeny and evolution of behaviours. An important tool of ethologists is the use of several methods of observation for gathering their data.

The aim of this study was to investigate the behavioural profile of neurologically impaired children with permanent CVI by means of ethological observations, in order to gain a better understanding of their visual functions. A series of behavioural elements (direct signs) and supportive or confirming behaviours (indirect signs) indicating some visual perception in the children are described.

\section{Methods}

Patients eligible for this study were children, under regular care of the cerebral palsy (CP) team of the Utrecht University Hospital, who lacked visual contact, had no stable fixation, and showed paradoxical visual behaviours which prevented visual function from being assessed by means of acuity cards or behavioural visual field techniques. Three boys and six girls, aged from 21 to 116 months (mean 5 years 3 months) were examined. All children received a complete neurological, ophthalmological, and orthoptical investigation. Neuroimagings (computed tomography (CT) or magnetic resonance imaging (MRI)) were analysed with special attention to the visual pathways. Informed consent was obtained from the parents after the research procedure had been fully explained.

The ethological observations were performed in a playroom of our hospital. Children were held on their parents' laps or were seated in adaptive wheelchairs. In a 15 minute session, observations of both their spontaneous activities and their activities under visual stimulation were performed. Video registrations of behaviours were made using two cameras placed in front of the child. The first camera recorded the subject's upper body and the test stimulus, while the second one was used to obtain a close up of the child's eyes. The choice of two cameras as opposite to just one was 
Table 1 Clinical and neuroradiological findings of children suffering from permanent cerebral visual impairment

\begin{tabular}{|c|c|c|c|c|c|c|c|c|}
\hline $\begin{array}{l}\text { Patient } \\
\text { No }\end{array}$ & Sex & $\begin{array}{l}\text { Age } \\
\text { (months) }\end{array}$ & Type of cerebral palsy & Type of analysis & Findings on neuroimaging & $\begin{array}{l}\text { Refraction } \\
\text { right eye (SE) }\end{array}$ & $\begin{array}{l}\text { Refraction } \\
\text { left eye (SE) }\end{array}$ & Cover test \\
\hline 1 & $\mathrm{~F}$ & 116 & Spastic tetraplegia & MRI and CT scan & $\begin{array}{l}\text { Parietal and occipital PVL associated } \\
\text { with corpum callusum hypoplasy }\end{array}$ & SF -7.25 & $\mathrm{SF}-7.00$ & $\mathrm{NP}$ \\
\hline 2 & M & 84 & Spastic tetraplegia & MRI and CT scan & $\begin{array}{l}\text { Diffuse retarded myelination } \\
\text { associated with corpum callusum } \\
\text { dysplasy }\end{array}$ & $\mathrm{SF}+1.00$ & $\mathrm{SF}+0.50$ & XT LE \\
\hline 3 & $\mathrm{~F}$ & 72 & Spastic tetraplegia & MRI & $\begin{array}{l}\text { Diffuse PVL along the left optic } \\
\text { radiation with posterior horn } \\
\text { ventricle dilatation }(\mathrm{L}>\mathrm{R})\end{array}$ & $\mathrm{SF}+0.25$ & $\mathrm{SF}+1.50$ & XT \# ET RE DVD \\
\hline 4 & $\mathrm{~F}$ & 54 & Hypotonic tetraplegia & MRI and CT scan & $\begin{array}{l}\text { Microcephaly with diffuse retarded } \\
\text { myelination }\end{array}$ & $\mathrm{SF}-1.00$ & $\mathrm{SF}-1.00$ & Orth \# ET RE DVD \\
\hline 5 & M & 70 & Spastic tetraplegia & MRI & $\begin{array}{l}\text { Severe cerebral atrophy with frontal } \\
\text { and occipital ventricle dilatation }\end{array}$ & $\mathrm{SF}+1.25$ & $\mathrm{SF}+1.25$ & Orthotropia \\
\hline 6 & $\mathrm{~F}$ & 21 & Left spastic hemiplegia & MRI and CT scan & $\begin{array}{l}\text { Cyst secundary to right } \\
\text { hemispherectomy (former right } \\
\text { hemimegalencephaly) }\end{array}$ & $\mathrm{SF}+1.50$ & $\mathrm{SF}+0.75$ & Orth \# XT LE \\
\hline 7 & $\mathrm{~F}$ & 49 & Spastic tetraplegia & MRI and CT scan & Extended occipital encephalocele & $\mathrm{SF}+2.00$ & $\mathrm{SF}+2.00$ & Orth \# XT RE \\
\hline 8 & $\mathrm{~F}$ & 45 & Spastic tetraplegia & MRI & $\begin{array}{l}\text { Pontocerebellar atrophy associated } \\
\text { with posterior ventricle dilatation }\end{array}$ & $\mathrm{SF}+1.50$ & $\mathrm{SF}+1.50$ & Orth \# XT RE \\
\hline 9 & M & 54 & Spastic tetraplegia & MRI and CT scan & $\begin{array}{l}\text { Extended bilateral cerebral atrophy } \\
\text { with posterior ventricle dilatation }\end{array}$ & $\mathrm{SF}+3.00$ & $\mathrm{SF}+3.00$ & Orth \# ET LE \\
\hline
\end{tabular}

$\mathrm{PVL}=$ periventricular leucomalacia $\mathrm{L}>\mathrm{R}=$ left side more than right side; $\mathrm{DVD}=$ dissociated vertical deviation;Orth $\# \mathrm{XT}=$ variable angle from orthotropia to exotropia; Orth \# ET = variable angle from orthotropia to esotropia; $\mathrm{XT} \# \mathrm{ET}=$ dyskinetic strabismus from exotropia to esotropia; $\mathrm{N}=$ normal; $\mathrm{NP}=$ not possible; $\mathrm{SE}=$ spheric equivalent.

made to capture more of the subtle visual responses. Both images were taped simultaneously and a time code was added using professional video mix equipment. Observations of activities under visual stimulation were done while objects were moved into the child's visual field at a distance varying from 20 to $80 \mathrm{~cm}$. Any auditory signals or tactile stimulation were carefully avoided. Based on the child's general level of visual attention, the objects used for stimulation were chosen by the observer on the basis of their colour, contrast, and size. To prevent the child from getting bored or becoming apathetic, the number of different stimuli used during each session varied from two to eight, with a mean number of five. The observer moved each object slowly towards the child several times from the left and right side as well as from above and from beneath. The videos of these observations were analysed by an ethologist using a video recorder equipped with slow motion. During this analysis, the video of each subject was first observed at normal speed to obtain general information about visual behaviour. Then meaningful sequences of behaviour, related in time to movements of the stimulus, and which appeared to indicate the visual perception of the stimulus, were detected. Furthermore, by using slow motion (qualitative analysis), detailed observations were made regarding the relation between the occurrence of behaviours in relation to the stimulus. General impression, degree of attention, peculiarities or special features, objects used for visual stimulation, and other visual behaviours were described in their sequence of occurrence. Finally, a list of behaviours indicating visual perception was compiled. When, during the presentation of an object, a child's eye, head, or hand movement in the direction of the stimulus was noticed, this behaviour was registered as a direct sign of visual perception. In addition, supportive or confirming behavioural elements were registered. We defined a behaviour as being supportive of visual perception if: (1) it was induced by a stimulus presentation;
(2) it was also observed during spontaneous activities not related to the stimulus presentation; (3) it was repeatedly shown in strict time relation with the presentation of the stimulus and during repeated presentations of different stimuli.

\section{Results}

NEUROLOGICAL EXAMINATION

All the children were affected by CP, classified according to the criteria of Hagberg et al..$^{21}$ The most common type of CP was a spastic tetraplegia (Table 1), most commonly associated with severe psychomotor retardation. In all subjects neuroimaging showed a moderate or severe involvement of the retrochiasmatic visual pathways, which supported the diagnosis of CVI.

OPHTHALMOLOGICAL EXAMINATION

Two of the children had refractive errors that needed correction. Strabismus with variable angle or dyskinetic strabismus ${ }^{22}$ was present in seven out of nine subjects. In almost all the children funduscopy revealed pale optic discs.

\section{ETHOLOGICAL EXAMINATION}

During the ethological observations four children were held on their parents' laps and five sat in adaptive wheelchairs. To illustrate the observational method used by the ethologist, the analysis of subject no 1 is reported in detail in the appendix.

Behaviours indicating the visual perception of a stimulus (direct signs) and supportive or confirming behaviours (indirect signs) are summarised in Table 2 and explained below. The use of supportive or confirming behaviours as indirect signs of visual perception can be substantiated by the fact that these behaviours were accompanied by direct signs in four subjects.

\section{DIRECT SIGNS}

Intermittent fixation towards the stimulus

Six children briefly fixated the visual target while moving their face towards the stimulus, 
Table 1 (continued)

\begin{tabular}{|c|c|c|c|c|}
\hline \multirow[b]{2}{*}{ Cover test near } & \multirow[b]{2}{*}{ Pattern of nystagmus } & \multirow[b]{2}{*}{ Pupil reflex } & \multicolumn{2}{|l|}{ Optic disc colour } \\
\hline & & & $R E$ & $L E$ \\
\hline NP & $\begin{array}{l}\text { Nystagmoid eye } \\
\text { movements }\end{array}$ & $\mathrm{N}$ & Pallor & Pallor \\
\hline XT LE & & $\mathrm{N}$ & Pallor & Pallor \\
\hline XT \# ET RE DVD & Latens & $\mathrm{N}$ & Temporal pallor & Temporal pallor \\
\hline Orth \# ET RE DVD & Latens & $\mathrm{N}$ & Mild pallor & Mild pallor \\
\hline Orthotropia & & $\mathrm{N}$ & $\mathrm{N}$ & $\mathrm{N}$ \\
\hline Orth \# XT LE & Manifest rotatory & Sluggish & Temporal pallor & Temporal pallor \\
\hline $\begin{array}{l}\text { Orth \# XT RE } \\
\text { Orth \# XT RE }\end{array}$ & Latens & $\begin{array}{l}\mathrm{N} \\
\text { Sluggish }\end{array}$ & $\begin{array}{l}\text { Chalk white } \\
\text { Pallor }\end{array}$ & $\begin{array}{l}\text { Chalk white } \\
\text { Pallor }\end{array}$ \\
\hline Orth \# ET LE & & $\mathrm{N}$ & $\begin{array}{l}\text { Optic disc } \\
\text { hypoplasia }\end{array}$ & $\begin{array}{l}\text { Optic disc } \\
\text { hypoplasia }\end{array}$ \\
\hline
\end{tabular}

whereas one girl (subject no 1) seemed to fixate with extrafoveal areas. Another girl (subject no 3) suffered from a dyskinetic strabismus which consistently limited her fixation ability. In the remaining two children (subject nos 2 and 7) it was impossible to register any sort of fixation.

Looking past the stimulus

At least three children looked past the stimulus (slightly above, beneath, or to the side of the stimulus) before reaching for or grabbing it.

\section{Head movements towards the stimulus}

Head movements towards the visual target, without moving any other part of the body, were seen in all subjects. Moreover, eye movements towards the stimulus, as in fixating or looking past the object, were frequently accompanied by a movement of the head.

Following the movement of a stimulus

A glance at the stimulus was strongly indicative of visual perception if the subject subsequently followed the object's movement by moving his/ her eyes, head, or arms in the same direction. All subjects exhibited this behaviour, with one exception (subject no 1).

\section{Reaching for the stimulus}

Seven children reached for the stimuli by lifting their hands in the direction of them. Their

Table 2 Behavioural characteristics of children with cerebral visual impairment

(1) Direct signs: behaviours indicating the visual perception of a stimulus

Intermittent fixation towards the stimulus

Looking past the stimulus

Head movements towards the stimulus

Following the movement of a stimulus

Reaching for the stimulus

Looking away while reaching the stimulus

(2) Indirect signs: supportive or confirming behaviours

Avoiding behaviour

Change of posture

Smiling

Blinking of eyes

Facial expression

Stereotypic behaviour reaching for the stimuli was often followed by touching, grabbing, hitting, or pushing away the objects.

Looking away while reaching for the stimulus Three children, after locating the object visually, turned their heads and their eyes in the opposite direction during the act of reaching for the object.

INDIRECT SIGNS

Visual or gaze avoiding

Visual or gaze avoiding is characterised by turning away the head and eyes from the stimulus with associated withdrawal of the upper body in response to a stimulus presentation. ${ }^{15}{ }^{23}$ In the current study four children exhibited such avoiding behaviour after visually locating the object. The behaviour varied from looking away from the stimulus (avoiding direct visual engagement with the stimulus), moving away head and upper body from the stimulus, to shrinking of the head and turning head and trunk to the complete opposite side of the stimulus. One girl (subject no 8) was frequently hanging her head forward after a stimulus presentation.

\section{Change of posture}

In three individuals a change of posture was a clear indicator of perception of an object. In particular, one subject (subject no 1) sat up straight just after a stimulus presentation, while another girl (subject no 6), who maintained constant albeit stiff motion, stopped short as soon as an object of interest was presented.

\section{Smiling}

Six subjects smiled while facing the stimulus, immediately after and during presentation. A smile was recorded as the corners of the mouth were drawn back and the mouth was closed or slightly opened.

\section{Blinking of eyes}

Active blinking of the eyes without fixation during the presentation of the stimulus was also considered expression of visual perception. Blinking of eyes was used by one child to change eye directions and to initiate a new saccadic movement towards the stimulus position. However, blinking of eyes was not associated with the typical head thrust normally found in congenital ocular motor apraxia.

\section{Facial expressions}

Small changes in a subject's facial expression were seen in response to stimulus presentations: lifting and wrinkling of eyebrows, sticking out the tongue, opening the mouth, smacking the lips, biting the underlip, and protruding the lips. Three children made rhythmic to and fro rocking movements, rotating in the hips. Others slowly waved their heads from side to side, repeatedly beat their knees, clapped their hands, wiggled their fingers, or showed hand flapping (a repetitive up and down movement of the hands). 
Stereotypic behaviours

Two subjects showed patterns of stereotypic behaviours in which a more or less fixed pattern of subsequent behaviours was repeated (for example, hand flapping behaviours or rocking movements).

\section{Discussion}

Detailed ethological observations of visual behaviour add new elements which allow ophthalmologists to gain a better understanding of visual functions or to indicate possible cerebral visual disorders at an early stage. Clinicians involved in the study of neurologically impaired children should be aware of the presence of every direct or indirect sign which may indicate the presence of residual vision and should acquaint parents with these signs, in order to facilitate their comprehension of the problem and to improve their visual communication with the child.

Several children with CVI showed intermittent fixation and looked at things only momentarily, as previously described in the literature. ${ }^{14}{ }^{24-27}$ Probably, this lack of visual attention decreases the amount of available visual information and contributes to poor perceptual performances. Thus, as the period of time they actually looked at the object was so short, a low visual acuity may result.

Looking past an object and then making corrective eye movements to the target was deemed a sign of a visual field defect. This behaviour was also observed in subjects with congenital homonymous hemianopia, who tend to eliminate head movements and substitute single, large, overshooting saccades with contraversive drift in order to acquire targets in the blind hemifield of vision. ${ }^{28}$

Head movements related to stimulus presentation could also be considered an important behavioural element because they may elicit ocular movements towards the localised object.

In order to follow a moving stimulus, several children needed sequential observation glances over a longer period. Although this has also been previously reported by Groenveld, ${ }^{29}$ no possible explanation was found for this behaviour.

Looking away to one or the other side during the act of reaching for the object, after it had been visually located, is probably used by the subject to orient the visual target to an area of residual visual field which is still functioning. In particular, Benton et al suggested the persistence of a spared temporal crescent, a peripheral part of the temporal field extending between 60 and 100 degrees in the horizontal meridian represented at the anterior part of the inferior tip of the calcarine fissure which may account for this behaviour. ${ }^{30}$ In contrast with Benton et al, Dewinsky and Good et al argued for a "Swiss cheese" visual field, formed by small islands of vision sustained by areas of preserved neuronal functions in the visual cortex. ${ }^{16} 31$

Fatigue or irritation can be associated with gaze avoiding. However, in several children gaze avoiding seemed to be an expression of selective visual attention, which may indicate an active attempt to reduce visual confusion.

Although the interpretation of smiling can be controversial, in our series a smile directly induced by a stimulus presentation was always considered an indirect sign of visual perception. In fact, in several children a smile followed direct signs of visual perception or was repeatedly shown in strict time relation with the presentation of the stimulus.

More difficult to explain is the presence of stereotypic behaviours in response to visual stimuli. As reported by Willemsen-Swinkels et al, a repetition of an invariant sequence of behaviours can be associated with positive moods and excitement after locating a particular stimulus and may compensate for overstimulating or understimulating environment. ${ }^{32}$ From this point of view, rocking movements or hand flapping behaviours may function to increase or decrease arousal of the child depending on the stimulus.

\section{Conclusion}

Visual functions of neurologically impaired children suffering from permanent CVI, who are unable to maintain a stable fixation at a desired point or who cannot direct their gaze to the stimulus location, are difficult to determine. Consequently, the interpretation of their visual capabilities can be a perplexing problem for ophthalmologists. By means of ethological analysis we registered a series of behaviours (direct signs) and supportive or confirming behavioural elements (indirect signs) indicating the visual perception of a stimulus.

These signs complement the list of features already described in the literature such as avoiding, chaotic eye movements, faking, or overlooking. ${ }^{14-18}$

Unique to this study is the introduction of ethological observational methods, which have shown to be useful and provide new insights in interpreting visual functions of children with permanent CVI. Further ethological studies by means of more sophisticated computerised observation programs ${ }^{33}$ could contribute to our understanding on neurobehavioural adaptations developed by neurologically impaired children with permanent damage along the retrochiasmatical visual pathways.

\section{Appendix}

ETHOLOGICAL ANALYSIS ON SUBJECT NO 1

The video showed a girl wearing glasses and sitting in a special wheelchair, which held her in a seated position by shoulder bands. When not visually fixating, her eyes were approximately at the horizontal meridian and movements of the eyes were smooth. Her head was sometimes slightly tilted backwards. She seemed to concentrate on detection of the stimulus all the time, without showing any lack of attention. She showed nystagmoid eye movements, looking directly up to either the left or right corner while lifting her eyebrows. This behaviour was not directly related to stimulus perception, but was used to search for any visual clues in her peripheral visual field. Facial expressions were sometimes shown, 
though not always related to a stimulus: smacking the lips, biting the underlip, and protruding the lips. In order of appearance, the objects used for visual stimulation were a small flashing light, a small football, a white ball on a stick, and a plastic yellow cow. Especially in the second half of the session she showed more behaviours indicating the perception of the object, in particular during presentations of the plastic yellow cow. A total of 31 meaningful sequences of stimulus presentation were selected for analysis. Presentations of objects were marked with certainty 16 times as perceived by the child. She always started with a movement of the head towards the stimulus but she had difficulties in spotting the objects and was seemingly unable to make a direct eye movement to it. She usually looked slightly past the object, without making corrective eye movements towards the target. Although we were unable to define aiming at the stimulus with certainty, she seemed to be looking slightly under the object of interest in most cases. On eight occasions the child clearly followed a movement of the stimulus with the head, the eyes, or with a movement of the arm. She reached for a stimulus nine times by lifting her left or right hand in the direction of the object. During the act of reaching she mostly looked past the stimulus at either side, although she looked away to the left side with a slight upward gaze several times. Reaching out for a cue was followed on three occasions with actually grabbing the stimulus. She smiled 11 times in relation to a stimulus. In particular, on one occasion she smiled in reaction to a stimulus presentation but as soon as the stimulus was taken away she stopped smiling. The moment the stimulus was placed at exactly the same position she started to smile again.

1 Van Nieuwenhuizen O. Cerebral visual disturbance in infantile encephalopathy. Dordrecht: Martinus Nijnhoff, 1987.

2 Lennerstrand G, Axelsson A. Visual acuity testing with prefLennerstrand G, Axelsson A. Visual acuity testing with pref-
erential looking in mental retardation. Acta Ophthalmol 1983;61:624-33.

3 Mayer DL, Fulton AB, Cummings M. Visual fields of infants assessed with a new perimetric tecnique. Invest Ophthalmol Vis Sci 1988;29:452-9.

4 Scher MS, Dobson V, Carpenter NA, et al. Visual and neurological outcome of infants with periventricula leukomalacia. Dev Med Child Neurol 1989;31:353-65.

5 Hertz GB, Rosenberg J. Effect of mental retardation and motor disability on testing with visual acuity cards. Dev Med Child Neurol 1992;34:115-22.

6 Schenk-Rootlieb AJF, Van Nieuwenhuizen O, Van der Graaf $\mathrm{Y}$, et al. The prevalence of cerebral visual disturbance in children with cerebral palsy. Dev Med Child Neurol 1992;34:473-8

7 Van Hof-Van Duin J, Heersema DJ, Groenendaal F, et al. Visual field and grating acuity development in low-risk pre- term infants during the first $2^{1 / 2}$ years after term. Behav Brain Res 1992;49:115-22.

8 Birch EE, Bane MC. Forced choice preferential looking acuity of children with cortical visual impairment. Dev Med Child Neurol 1991;33:722-9.

9 Luna B, Dobson V, Scher MS, et al. Grating acuity and visual field development in infants following perinatal asphyxia. Dev Med Child Neurol 1995;37:330-44.

10 Eken P, Van Nieuwenhuizen O, Van der Graaf Y, et al. Relation between neonatal cranial ultrasound abnormalities and cerebral visual impairment in infancy. Dev Med Child Neurol 1994;36:3-15.

11 Ipata AE, Cioni G, Bottai $P$, et al. Acuity card testing in children with cerebral palsy related to magnetic resonance images, mental levels and motor abilities. Brain Dev 1994; 16:195-203.

12 Mackie RT, McCulloch DL. Assessment of visual acuity in multiply handicapped children. Br F Ophthalmol 1995;79: $290-6$

3 Sireteanu R. Development of visual field results from human and animal studies. In:Vital-Durand F, Aktinson J, Braddick O, eds. Infant vision. Oxford: Oxford University Press, 1996:17-22.

14 Jan EJ, Groenveld M, Sykanda AM, et al. Behavioural characteristics of children with cortical visual impairment. Dev Med Child Neurol 1987;29:571-6

15 Papini M, Pasquinelli A. Gaze avoiding in childhood and adolescence. Gaslini 1995;27:31-3.

16 Good WV, Jan JE, DeSa L, et al. Cortical visual impairment in children. Surv Ophthalmol 1994;38:351-64.

17 Whiting S, Jan JE, Wong PKH, et al. Permanent cortical visual impairment in children. Dev Med Child Neurol 1985; 27:730-9.

18 Good WV, Crain LS, Quint RD, et al. Overlooking: a sign of bilateral central scotomata in children. Dev Med Child Neurol 1992;34:61

19 Jan EJ, Groenveld M, Connolly MD. Head shaking by visually impaired children: a voluntary neuro-visual adaptation which can be confused with spasmus nutans. Dev Med Which can be confused with

20 Jan JE, Groenveld M, Anderson DP. Photophobia and cortical visual impairment. Dev Med Child Neurol 1993;35:11522 .

21 Hagberg B, Hagberg G, Olow I. The changing panorama of cerebral palsy in Sweden:1954-1970. II Analysis of various syndromes. Acta Paediatr Scand 1975;64:193-200.

22 Buckley E, Seaber JH. Dyskinetic strabismus as a sign of cerebral palsy. Am f Ophthalmol 1981;91:652-7.

23 Pasquinelli A, Papini M. Morphology and timing of gaze avoiding in extrapyramidal disorders of childhood and adolescence. Gaslini 1995;27:34-6.

24 Regal DM, Ashmead DH, Salapatek P. The coordination of eye and head movements during early infancy: a selective review. Behav Brain Res 1983;10:125-32.

25 Wong VC. Cortical blindness in children: a study of etiology and prognosis. Pediatr Neurol 1991;7:178-84.

26 Bane MC, Birch EE. VEP acuity, FPL acuity and visual behaviour of visually impaired infants. $\mathcal{F}$ Pediatr Ophthalmol Strabismus 1992;29:202-9.

27 Kivlin JD. Cortical blindness and delayed visual development in infants. Am Orthoptic f 1993;43:107-14.

28 Zangemaister WH, Meienberg O, Stark L, et al. Eye-hand coordination of homonymous hemianopia. 7 Neurol 1982; 226:243-54.

29 Groenveld M. Effects of visual disability on behaviour and family. In: Fielder AR, Best AB, Bax MCO, eds. The managment of visual impairment in childhood. Cambridge: Cambridge University Press, 1993:64.

30 Benton S, Levy I, Swash M. Vision in the temporal crescent in occipital infarction. Brain 1980;103:83-97.

1 Dewinsky O. Disorders of visual processing. In: Arnold E, ed. Behavioural neurology: 100 maxims. London: Hodder and Stoughton, 1992:167-9.

32 Willemsen-Swinkels SHN, Buitelaar JK, Dekker M, et al. Subtyping stereotypic behaviour in children: the association between stereotypic behaviour, mood and heart rate. Utrecht: Utrecht University Press, 1995:124-35.

33 Noldus LPJJ. The OBSERVER: a software system for collection and analysis of observational data. Behavioural Research Methods, Instruments \& Computers 1991;23:415-29. 